\title{
Don Melchor Carlos Inca, el inca mestizo: Los Carlos Inca en el siglo XVII de la sociedad cusqueña
}

\author{
Donato Amado Gonzales
}

\section{RESUMEN}

En 1539, don Cristóbal Paullo, uno de los hijos del inca Huayna Cápac, fue nombrado «inca» como parte de una estrategia política de los españoles. Desde entonces tuvo acceso a encomiendas de indios. Don Cristóbal se casó con doña Catalina Tocto Oxica y tuvieron dos hijos: don Carlos Inquill Topa y don Felipe Inquill Topa. Don Carlos Inquil Topa se casó con doña María Esquivel Amarilla y tuvieron un solo hijo llamado Melchor Carlos Inca. El nacimiento de Melchor fue visto por la población nativa como un gran acontecimiento pues había nacido un «rey inca», el cual incluso llegó a ser temido por los funcionarios españoles coloniales al saber que se referían a él como «Cápac Inca». Don Melchor Carlos Inca se identificaba como nieto de don Cristóbal Paullo Inca y bisnieto del inca Huayna Cápac. Se convirtió en un personaje importante dentro de la sociedad virreinal cusqueña. Don Melchor fue bautizado y se casó con doña Leonor Arias Carrasco, hija del conquistador Pedro Alon- 
so Carrasco, ambos eventos fueron significativos para la sociedad cusqueña. La encomienda de Pichigua, de propiedad de don Melchor, era de mucha importancia económica y social, por ello para mantener esta encomienda y sus actividades sociales/políticas, se vio obligado a vender e hipotecar por vía de censo parte de su patrimonio. En 1599, el virrey Luis de Velasco dio una comisión al capitán Antonio Pereira (regidor perpetuo) para averiguar la ascendencia y los servicios de los ancestros de don Melchor. En 1603, don Melchor viajó a España para reclamar sus privilegios y logró su inclusión como Caballero de la Orden de Santiago. La descendencia de Cristóbal Paullo Inca logró establecer y constituir la capilla de Nuestra Señora de Guadalupe en el convento e iglesia de San Francisco, donde tuvieron el honor de tener una bóveda funeraria, la cual fue cuidada y mantenida por sus descendientes hasta el siglo XVII.

Palabras clave: Privilegios, Cápac inca, probanza, testamentos, capilla

\section{Abstract}

In 1539, don Cristobal Paullo, one of the sons of the Inca ruler Huayna Capac, was named «Inca» as a political strategy of the Spaniards. Since then, he received an encomienda. Don Cristobal was married to doña Catalina Tocto Oxica and had two sons, don Carlos Inquill Topa and don Felipe Inquill Topa. Don Carlos Inquil Topa married doña Maria Esquivel Amarilla and had only one son named Melchor Carlos Inca. The birth of Melchor was seen by the native population as a great event because an "Inca king" had been born, he even became feared by the colonial Spanish officials when they knew he was referred as the "Capac Inca». Don Melchor Carlos Inca identified himself as grandson of don Cristobal Paullo Inca and great-grandson of the Inca Huayna Capac. He became an important figure within the Cuzcoss colonial society. Don Melchor was baptized and married doña Leonor Arias Carrasco, daughter of the Spanish conquistador Pedro Alonso Carrasco, both events were meaningful for Cusco society. Don Melchors' encomienda of Pichigua was of great economic and social importance, in order to maintain this encomienda and his social/political activities, he had 
to sell or mortgage part of his inherited patrimony. In 1599, the Viceroy Luis de Velasco ordered captain Antonio Pereira («regidor perpetuo») to ascertain the ancestry and services of don Mechor and his ancestors. In 1603, don Melchor traveled to Spain in order to claim his privileges and succeeded at obtaining a knighthood in the Order of Santiago. The descendants of Cristóbal Paullo Inca established the Chapel of Our Lady of Guadalupe in the Convent and Church of San Francisco where they had the honour of having a burial vault which was carefully guarded and maintained by their descendants until $17^{\text {th }}$ Century.

Keywords: Offspring, Privileges, Cápac Inca, Certified Proofs Of Merits and Services

\section{INTRODUCCIÓN}

RECUERdo CON NOSTALGia y mucho cariño las enseñanzas recibidas y las conversaciones sostenidas con Sabine MacCormark en torno de la enigmática descendencia inca en nuestro periodo colonial. Sus frecuentes visitas a la ciudad del Cusco, así como nuestras pláticas en la Universidad de Notre Dame en los EE.UU. me permitieron conocer a Sabine, quien destacó como historiadora del mundo andino, siendo quien mejor entendió y explicó la visión europea de los cronistas del siglo XVI y XVII. A través de tertulias en forma presencial y en correspondencia por correo electrónico, intercambiamos información del Archivo Regional del Cusco. El Cusco de los incas del siglo XVI fue un tema crucial discutido reiteradamente. El papel de los incas de Vilcabamba, encabezados por Manco Inca y el de los incas del Cusco, liderados por Paullo Inca, nos permiten destacar un hecho que toma notoriedad en la segunda mitad del siglo XVI, donde surge un tercer grupo de descendientes incas como intermediarios de estos dos grupos, encabezados por Diego Sayre Tupa, quien salió de Vilcabamba atraído por los privilegios que le habían ofrecido, estableciéndose en Yucay el marquesado de Oro- 
pesa. La Corona española pensó que con la salida de Sayre Tupa se pacificaría Vilcabamba, pero no fue así. Tito Cusi Yupanqui y Tupa Amaru optaron por una postura más radical. De esta manera, podemos referir que en ese periodo de tiempo se lograron constituir los incas de Vilcabamba, el marquesado de Oropesa de Yucay y las Ocho Parroquias de la ciudad del Cusco. Los incas del Cusco, estaban dirigidos por la descendencia de Paullo Tupa Inca, su hijo Carlos Inca y el nieto Melchor Carlos Inca. A Sabine, le interesó la identidad de «Paullu Topainca», indagando en los archivos para lograr entender la personalidad y la participación política de este descendiente de la élite del Tahuantisuyo frente a los españoles. Por mi parte, encontré mayores interrogantes en la gestión de sus privilegios y en la descendencia de don Melchor Carlos Inca hacia finales del siglo XVI y durante el siglo XVII.

Sabine, investigando en los archivos sobre la ascendencia de la parentela liderada por Cristóbal Paullo Inca, consiguió una copia fotostática de todo el libro denominado «papeles referentes a la ascendencia de Juan Carlos Inga» (1539-1626, 330 x 220 mm, abierto: 407 mm., Biblioteca Nacional de Madrid, mss. 20193). ${ }^{1}$ Estos documentos eran nada menos que la probanza presentada por don Melchor Carlos Inca respecto a los títulos de las encomiendas suyas y de su abuelo, sosteniendo su ascendencia y sus privilegios. Este libro corrió por mis ojos para la transcripción paleográfica siendo una experiencia extraordinaria donde aprendí qué era una probanza de privilegios. Sin embargo esta información resultó insuficiente

1 La fotocopia de este libro me fue facilitada por ella. Luego surgieron una serie de discusiones respecto a la descendencia de Cristóbal Paullo Inca. Por ejemplo, existe un documento que rescata la palabra de testigos relacionados a la nobleza inca y fue presentado por Melchor Carlos Inca en 1599. Era información particularmente importante para el estudio de las panacas reales, pues retrataba cómo fue el matrimonio del inca Huayna Cápac con la coya Añas Colque. La versión de estos testigos trae información riquísima respecto a la función que cumplían ciertos espacios que más adelante se volverían barrios. Haucaypata es una muestra de ello y quiere decir lugar de deleite y regocijo pese a que se ha generalizado la idea de que era la plaza de los lamentos o el llanto. 
para poder explicar y entender a los «Carlos Inca» durante el siglo XVII; además, carecía de algunas precisiones respecto a su desenvolvimiento dentro de la sociedad cusqueña. Por ello, era necesario indagar en documentos referentes a esta familia, encontrándonos con algunos testamentos pertenecientes a esta descendencia inca. Para dicha tarea, asumí una búsqueda exhaustiva en el Archivo Regional del Cusco, producto de ello se recopiló una buena cantidad de testamentos de los «Carlos Inca» en los protocolos notariales del siglo XVI y XVII.

El estudio de los folios del Archivo Regional del Cusco y el manuscrito de la Biblioteca Nacional de Madrid me permitió entender cómo la descendencia de don Cristóbal Paullo Inca -hijo del Inca Huayna Cápac- instituyó los oficios y cargos de privilegio como Alcalde Mayor, Alguacil Mayor y Alférez Real de los Incas de las Ocho Parroquias de la Ciudad del Cusco. Dichos cargos fueron reservados sólo para los descendientes del inca Huayna Cápac. En esta perspectiva, consideramos como una personalidad preponderante a don Melchor Carlos Inca, quien adoptó una postura española denominándose «vecino de la ciudad del Cusco» para adquirir el Alferazgo General de la ciudad exclusivamente destinado a beneméritos españoles o descendientes de los primeros conquistadores. Ya en España, logró uno de los mayores privilegios al cual un militar español podía aspirar: el título de caballero de la Orden de Santiago. Luego de su muerte esta hidalguía sería heredada por su hijo Juan Melchor Carlos Inca.

\section{La descendencia de don Cristóbal Paullo Inca}

Los españoles, entre Cajamarca y Cusco, entendieron que debían buscar un sucesor inca legítimo por la línea de Huáscar. Este personaje fue Manco Inca, quien prácticamente cogobernó junto a 
los españoles. En Cusco, Manco Inca empezó a gobernar al estilo inca, debía restablecer el orden y, con algunas restricciones ejecutaba costumbres andinas. Sin embargo, su situación se tornó paradójica. Por una parte, debía recibir los honores reservados al inca; por otra, los españoles siempre ávidos de oro le humillaron reiteradamente. Esto último y otras razones motivan la decisión de reconquistar el gobierno de los incas, asumiendo la resistencia contra los españoles desde Vilcabamba. Ante esto, ellos deciden buscar un aliado coyuntural, que es Paullo Inca, quien a pesar de no ser sucesor legítimo se tornó en un líder nato cuando los españoles sitiaron la ciudad del Cusco. Paullo se convirtió en embajador de los españoles en Vilcabamba, sin embargo en 1549, antes de concretar las gestiones que propiciaron el viaje, en el tramo del camino Cusco-Vilcabamba, enfermó y murió.

Don Cristóbal Paullo Inca, al ser hijo de Huayna Cápac, asumió el poder como Inca en 1537. Obedeció a los españoles e hizo levantar el cerco de la ciudad reduciendo a muchas provincias del Collao y los Carangas que se habían alzado contra los españoles (Vázquez de Espinoza 1948: 550-552). En un principio, Paullo Inca fue tomado con desconfianza -especialmente por los pizarristas-, debido al temor de la relación «trato y concierto» que pudiera mantener con Manco Inca y los almagristas. No era para menos, Paullo Inca fue «señor de cuatro mil indios» que llevaba en su compañía, los cuales fueron de mucha ayuda para los españoles. Pero sucede algo particular en este punto, al final de todas las campañas realizadas a favor de los invasores pidió ser bautizado y convertido al cristianismo por el comendador fray Juan Pérez Arriscado, de la Orden y Caballería de San Juan, quien le otorgó el nombre de Cristóbal Paullo Inca e hizo lo propio con su mujer doña Catalina Tocto Oxica, «descendiente de Inga Roca del aillu Vicaquirao». La Santa Iglesia legitimó el matrimonio del cual nacieron «don Carlos Inquill Topa y don Felipe Inquill Topa». Siendo testigos de estos actos de conversión muchos incas principales y sus seguidores pidieron ser 
bautizados. Tal es el caso de don García Cayo Topa, don Felipe Cari Topa, don Juan Paccac o Pascac y don Juan Suna, entre otros.

De acuerdo a la legislación española, don Carlos Inquil Topa debía ser heredero del mayorazgo. Este personaje se educó muy bien, siendo condiscípulo del Inca Garcilaso de la Vega en la escuela, llegó a ser escribano y muy buen hombre de a caballo, diestro en las armas así como buen músico.

Se casó posteriormente con «doña María Esquivel Amarilla, señora principal, natural de Trujillo en los Reinos de España», con quien tuvieron un solo hijo llamado Melchor Carlos Inca. El nacimiento de Melchor Carlos Inca fue visto por la población nativa como un gran acontecimiento pues había nacido un «rey inca», el cual incluso llegó a ser temido por los propios funcionarios coloniales al saber que lo nombraban como «Capac Inca». Le llevaban muchos regalos, tanto comida como carneros diciendo «muchay cuscayqui çapa ynga» ${ }^{2}$, «adorado el único señor inca». ${ }^{3}$ Los mismos Titu Cusi Yupanqui y Túpac Amaru Inca salieron de Vilcabamba para visitarlo en la ceremonia de bautizo, manteniéndose ocultos en la casa de Cristóbal Paullo Inca (Bauer y Halac-Higashimori 2013: 38).

Más adelante, entre cierta incertidumbre, don Carlos Inca y Felipe Sayre Tupa, entre otros, fueron acusados por haber jurado como cápac a Melchor Carlos Inca. Evidentemente, Toledo lo interpretó como si lo hubieran jurado como «rey». Pese a la confusión no problematizaron más el tema y, de todas maneras, Melchor Carlos Inca fue el heredero del patrimonio familiar de Paullo y quien conservó un preponderante lugar en la sociedad cusqueña.

2 «Expediente de probanza presentada por Melchor Carlos Ynga, 1626. Documentación que forma parte de la presente publicación». Esta denominación aparece en las declaraciones del testigo Gonçalo Barbosa, el 17 de octubre de 1599, f. 96.

3 Sabine MacCormack (2004) encontró en el archivo de la Biblioteca Nacional de Madrid de España, un valioso documento que es la probanza presentada por don Melchor Carlos Inca, la cual ha estudiado cuidadosamente para tratar de explicar la identidad de Paullo Topa Inca y de su descendencia. 
Don Melchor Carlos Inca, hijo de don Carlos Inca y de doña María Esquivel, nieto de don Cristóbal Paullo Inca y bisnieto del Inca Huayna Cápac, se convirtió en un personaje bastante importante dentro de la sociedad virreinal cusqueña. Se casó con doña Leonor Arias Carrasco, hija del conquistador Pedro Alonso Carrasco y tanto el bautizo como el matrimonio fueron todo un acontecimiento en Cusco. Para ese momento de nuestra historia, es decapitado don Felipe Túpac Amaru, considerado legítimo descendiente de Manco Inca; y doña Beatriz Coya, hija de don Diego Sayre Tupa, contraería después matrimonio, en pacto político, con Martín García de Loyola del marquesado de Oropesa. Este momento aparentemente era el adecuado y preciso para que don Melchor Carlos Inca pasara a convertirse en líder absoluto de los descendientes incas.

Sin embargo, hacia la década de 1590, optó por una categoría social importante dentro de la sociedad cusqueña al ser considerado «vecino de la ciudad del Cuzco», un privilegio reservado solo para los encomenderos, derecho que adquirió debido a su administración de las encomiendas heredadas de su padre y de su abuelo. En otro sentido, el hecho de que don Melchor Carlos Inca se considerara como último descendiente inca, denotaba un temperamento que causaba problemas a la autoridad colonial. Para que no siguiera generándolos y para evitar la presencia de un sucesor, fue enviado a España en 1600. Allá acudió a la corte para recibir mercedes que le habían propuesto por los servicios que su abuelo hizo en la «conquista y pacificación del Perú». Le favorecía enormemente el haber sido bisnieto por línea varonil de Huayna Cápac y, como tal, era uno de los pocos de sangre real por no decir el más notorio y principal. Atendiendo sus pedidos, se le permutaron sus encomiendas por rentas fijas en la metrópoli. En 1604, suplicó que en lugar de la «borla real o mascapaicha», que le debía ser entregada por su ascendencia inca, se le discerniera el cargo de almirante, condestable 
del Perú o algún título de conde, duque o marqués con estado anexo (Lohmann Villena 1948: 72). En atención a ello, le dieron el título de caballero de la Orden de Santiago.

Por otro lado, una de las acciones tomadas por Melchor Carlos Inca fue intentar adquirir el cargo de Alférez Real de la ciudad del Cusco, al que sólo los españoles conquistadores y beneméritos tuvieron derecho como cargo de privilegio. Es así como encontramos la solicitud que realiza, en 1594, don Miguel de Berrio, quien pidiera el otorgamiento por vía merced del oficio de «Alférez General de la ciudad del Cuzco». De acuerdo al fundamento de su petición, el Alferazgo Mayor de la ciudad del Cusco le pertenecía a su abuelo don Juan Berrio Villavicencio, quien acompañó al presidente Vaca de Castro hasta que se dio batalla a los almagristas para después, retornar con el estandarte real hasta la ciudad del Cusco. Así mismo, su padre, Juan de Berrio de Villavicencio, había servido en la jornada de Vilcabamba y en todas las ocasiones que le tocó servir lo hizo «con mucho gusto». Por ello, en reconocimiento, don Miguel de Berrio había usado el oficio de Alférez Mayor de la ciudad durante cuatro años, hasta que se enteró que dicho oficio había resultado vendido por vía de remate público a favor de don Melchor Carlos Inca. A pesar de ello, en reconocimiento del servicio prestado por el abuelo y padre de don Miguel de Berrio, el virrey confirmó la merced del oficio de Alférez Mayor de la ciudad, a favor de don Miguel, el 12 de noviembre de $1594 .{ }^{4}$

$4 \quad$ ARC. Libro de Cabildo, n. 8 (1549-1597). F. 112: «Merced del oficio de Alférez Mayor de la Ciudad del Cuzco a favor de don Miguel de Berrio. En la Ciudad de Los Reyes, 12 de noviembre de 1594». 


\section{Gestión y probanza de don Melchor Carlos Inca}

Don Melchor Carlos Inca hacia la década del 1590 sostuvo una intensa actividad para gestionar la herencia de su padre y de su abuelo a través de su curador Diego de Escobar. La administración de la encomienda de Pichigua era de mucha importancia económica para don Melchor, por lo que otorgó poderes a diferentes personas para que realicen cobranzas a los corregidores de Canas y Canchis así como de los tributos en especies y dinero a los curacas principales de Pichigua. ${ }^{5}$ Por otra parte, debía enfrentar diferentes pleitos en defensa de sus intereses y es así como, en 1596, don Melchor otorgó poder a tres procuradores de causas de la ciudad del Cusco los cuales eran Juan de Cepeda, Juan de Salas y Francisco López Remusgo; los tres juntos debían representarlo en todos sus «pleitos, causas y negocios civiles o criminales». ${ }^{6}$

Para mantener sus actividades sociales y políticas, don Melchor debió verse obligado a vender e hipotecar por vía de censos parte del patrimonio heredado de sus padres. De esta manera, en marzo de 1597, vendió a favor de Juan de la Moneda una propiedad destinada a estancia de ganado y cultivo de tierras en el valle del Ichobamba, en el asiento de Mutocancha, con chozas y 50 ovejas en cantidad de 500 pesos. $^{7}$ Un mes después, don Melchor otorga

$5 \quad$ ARC. Joan de Olave, Prot. 7 (1595-1596), f. 770. «Don Melchor Carlos Ynga vecino de la ciudad del Cuzco, otorga poder y cesión e causa propia a favor de Jusepe de Villela, para que cobre del corregidor del partido de Pichigua y de los indios llaveros y caxas de comunidad de los caciques principales, 270 pesos» (Cusco, 28 de noviembre de 1596).

6 ARC. Salas Antonio de, Prot. 15 (1596-1597), f. 237. «Don Melchor Carlos Ynga y Rui Diaz de Matamoros vecino de esta ciudad del Cuzco, otorgan poder cumplido a favor de Juan de Cepeda y a Juan de Salas y a Francisco López Remusgo procuradores de causa del número de esta ciudad a todos tres juntos, para en todos sus pleitos causas y negocios civiles y criminales» (Cusco, 9 de junio de 1596).

7 ARC. Salas Antonio de, Prot. 15 (1596-1597), f. 733. «Don Melchor Carlos Ynga, vecino de la gran ciudad el Cuzco, vende a favor de Juan de la Moneda, una estancia para ganado y con tierras para sementera». 
en venta por la cantidad de 200 pesos a favor de Alonso Arias de Girón, morador de la ciudad del Cusco, dos topos de tierras para sembrar maíz con acceso a riego «donde dicen Añaypampa», en la parroquia de San Sebastián en el valle del Cusco. ${ }^{8}$

El dinero de la venta de tierras y estancias no debió serle suficiente por lo que en 1598 tuvo que acudir acompañado de sus fiadores a vender por vía de censo, a favor del convento de Nuestra Señora de las Mercedes, 114 pesos de renta anual, por el principal préstamo o hipoteca de 1596 pesos. Para la seguridad del préstamo, hipotecó las casas principales en la calle del «Comendador de Pedro Alonso Carrasco», las casas principales de la fortaleza de Colcampata de la parroquia de San Cristóbal, las casas principales y huerta del valle y pueblo de Yucay, las tierras de Silque del pueblo de Ollantaytambo y también las tierras y huertas del valle de Limatambo.

En 1602, en la Ciudad de Los Reyes, don Melchor Carlos Inca, juntó toda la documentación que era parte de la gestión de los bienes patrimoniales de sus antepasados. Los documentos que, según él, eran prioritarios fueron los títulos de las encomiendas que había logrado heredar. En primer lugar, estaba la cédula de la encomienda de Pichigua otorgada por el marqués don Francisco Pizarro, el 20 de abril de 1539; en segundo lugar, las cédulas de aprobación de la encomienda, por parte del licenciado Cristóbal Vaca de Castro y los títulos de la encomienda otorgadas por el virrey don Martín Enríquez, en favor de don Melchor Carlos Inca, a través de su tutora y curadora, su madre doña María de Esquivel,

8 ARC. Salas Antonio de, Prot. 15 (1596-1597), f. 606v. «Don Melchor Carlos Ynga vecino de esta ciudad del Cuzco vende a favor de Alonso Arias de Jirón morador en la dicha ciudad, dos topos de tierras de sembrar maiz, en el valle de esta ciudad, entre esta dicha ciudad y San Sebastián a donde dicen Añaypampa, en 200 pesos» (Cusco, 14 de mayo de 1597).

9 ARC. Cristóbal de Lucero, Prot. 8 (1598), f. 454. «Don Melchor Carlos Ynga vecino que soy de la gran ciudad del Cuzco, vende por vía de censos a favor del Convento de Nuestra Señora de las Mercedes 114 pesos de renta anual los impone sobre por el precio de 1596 pesos» (Cusco, 10 de agosto de 1598). 
el 14 de mayo de 1582. La cédula real del 31 de marzo de 1596 dispone se haga la demostración de la filiación, descendencia y calidad de don Melchor Carlos Inca. El 4 de marzo de 1599, el virrey Luis de Velasco, atendiendo la cédula real, nombra por comisión al capitán Antonio Pereira, vecino y regidor perpetuo, para que haga la averiguación e informe sobre la ascendencia y servicios de los ancestros de Melchor Carlos Inca.

El 17 de mayo de 1596, don Antonio Pereira ejecuta la disposición de la cédula real y la comisión dada por el virrey Luis de Velasco. La probanza contiene la demostración del matrimonio de Huayna Cápac con Añas Colque, de cuyo matrimonio nace Cristóbal Paullo Tupa Inca. Del matrimonio de Cristóbal Paulo con doña Catalina Tocto Usica, nace Carlos Inca. Don Carlos Inca se casó con María de Esquivel, de cuyo casamiento nace Melchor Carlos Inca. Se enfatiza la atención, crianza y bautizo de don Melchor Carlos Inca, señalando que los padrinos de bautizo fueron el virrey don Francisco de Toledo y doña María Arias. Melchor Carlos Inca desposó a doña Leonor Arias, hija de don Pedro Alonso Carrasco y de doña Isabel Fernández Cabeza, vecinos notables de la ciudad del Cusco. Este árbol genealógico sustenta el merecimiento de la renta que debe tener don Melchor Carlos Inca. Puntualmente aparecen los servicios prestados por Paullo Inca a favor de los españoles y cómo él y su esposa se convirtieron en cristianos como ejemplo para los demás nobles. En esta orden aparecen los servicios prestados por Carlos Inca y cómo el virrey don Martín Enríquez encomendó el pueblo de Hatun Cana a favor de Melchor Carlos Inca. Por las razones expuestas, se solicitaba se le diera la merced de 30,000 pesos de renta perpetua al año.

El 17 de mayo de 1599, el capitán don Antonio Pereira, vecino y regidor perpetuo de la ciudad del Cusco, por orden del virrey don Luis de Velasco, hizo averiguaciones y recogió la información respecto a los servicios prestados por los antecesores de don Melchor Carlos Inca. Se comenzó con la presentación de los testigos espa- 
ñoles y luego hablaron los descendientes incas, quienes destacaron la personalidad de don Melchor Carlos Inca y ponderaron las fiestas de su bautizo y nacimiento, en la que destacan las muchas fiestas y regocijo por parte de españoles y descendientes incas así como deudos, caciques principales y el común de indígenas de la ciudad, adheridos a los pueblos que acudieron a dichas fiestas.

Vio este testigo como muchos dellos trayan camaricos de comidas y carneros y corderos y otros rregalos a los dhos don Carlos y doña María desquibel sus padres diziendo muchay cuscayqui çapa ynga que quiere dezir solo señor y mui deseado por ellos besando los pies a los dhos sus padres y haziendo otras cossas de mucho amor que les tenían y de lo mucho que se avian holgado y por aver nazido el dho don Melchor rrespeto de no aver otros herederos por linea rrecta de baron del dho Guainacapc mas que /f. 96v/ el dho don Melchor al qual vio este testigo. ${ }^{10}$

Los testigos nativos destacan que en el bautizo de Melchor Carlos Inca, los españoles corrieron toros así como los hanan-cuzco y hurin-cuzco ofrecieron danzas. Todos ofrendaban «regalos, ropas, carneros y corderos de la tierra, gallinas y pollos, y otras cosas a los dichosos don Carlos y doña Isabel de Esquivel». Asimismo, los testigos afirmaban acerca de la personalidad de Melchor Carlos Inca, su padre y abuelo, que desde que se convirtieron al cristianismo anduvieron a «usanza y traje español». Aquí la afirmación:

trayendo su perssona mui lustrossamente como lo a fecho el susodho desde que tuvo hedad para ello como caballero hijo dalgo sirviendose de criados españoles y esclabos teniendo muchos caballos y mulas y gaezes y otros aderessos nezesarios para su ornato tratando y comunicando siempre con los caballeros vezinos y gente prin /f. 58v/ çipal de los de esta ciudad de los quales y de toda la demas gente della a sido y es mui bien visto

10 BNM, 1626, f. 96v. «Testigo Gonzalo Barbosa, de más de 63 años, nacido en la ciudad del Cuzco, donde es morador y vive». Cusco, 17 de octubre de 1599. 
y estimado ansi por sus buenas partes como por ser hijo y nieto y bisnieto de los señores naturales que fueron deste rreyno andando vestido el dho don Melchor carlos ynga e los dhos don Xpobal paullo topa y don Carlos su padre y abuelo todo el tienpo que este testigo les conozio y conoze como españoles en que se a abentajado el dho don Melchor a todos los de su tienpo el qual en los Regozijos fiestas que se an fecho en esta ciudad a sido sienpre uno de ellos y el mas luzido sacando quadrillas a su costa de que hera caudillo. ${ }^{11}$

Definitivamente, Melchor Carlos Inca adoptó la personalidad de un español, destacando en fiestas y reuniones. Para 1599, «don Melchor Carlos Inga» ya estaba casado en primeras nupcias con doña Leonor Arias Carrasco, también natural del Cusco e hija de don Pedro Alonso Carrasco y de doña Isabel Fernández Cabeza. En segundas nupcias se casó con doña María de Silva, nacida en Madrid, y con la cual tuvo un hijo llamado don Felipe Carlos Inga quien murió prematuramente. Este segundo matrimonio se había celebrado al habérsele otorgado un poder especial para casarse y habiendo dado palabra de matrimonio, sin embargo, tras el nacimiento de un hijo y su temprana muerte, Melchor Carlos Inga impidió pudiera efectuarse la ceremonia canónica (Casado 2005). De esta manera, don Melchor Carlos Inca en España no dejó ningún descendiente legítimo; sin embargo, el memorial de Juan Bustamante señala que «don Melchor Carlos Ynga, natural de la ciudad del Cusco y de los Reinos del Perú, obedeciendo el mandato Real de la Corona española, y de don Felipe III, fue llamado a la Corte de Madrid para asegurar el bienestar de su hijo que había sido dejado al cuidado de Pedro Alonso Carrasco, quien fuera su suegro al haberse casado con su hija doña Leonor Arias Carrasco, con quien nunca llegó a tener hijo alguno». El hijo en mención era fruto de

11 BNM, 1626, f. 58v. «El testigo fue Pedro Guerrero de 78 años, quien fue morador de la ciudad del Cuzco». 
la relación sostenida con doña Francisca de Chávez, siendo ambos solteros en $1592 .{ }^{12}$

Don Melchor Carlos Inca falleció en Alcalá de Henares el día 2 de octubre de 1610. Tenemos referencias de que el testamento de Melchor Carlos Inca se encontraría en el mismo lugar, pues con fecha 4 de octubre de 1610 se abrió el sobre testamentario «en el que pedía el traslado de su restos a Cuzco para recibir sepultura en el convento de San Francisco...» (Casado 2005: 3). Doña María de Silva, su legítima esposa, sobrevivió a Melchor Carlos Inca quien había tenido otros cinco hijos ilegítimos, los que eran don Juan Melchor Carlos Inca, Juana Yupanqui, Juan Carlos Inca, doña María Coya y Melchora Clara Coya. Por ello, a su muerte se inició un pleito entre sus hijos ilegítimos y María Silva, quien finalmente interpuso una pensión de 2,000 ducados. Ambas partes llegaron a un acuerdo celebrado en Madrid el 9 de octubre de 1619.

En esta línea parental sigue don Juan Melchor Carlos Inca, hijo de don Melchor Carlos Inca con doña Francisca de Chávez, hija de Alonso Ortiz de Montesdoca y de Inés de Chávez. Doña Francisca era feligresa de la Parroquia del Hospital de Naturales, por ello pidió que sus restos sean enterrados junto a la sepultura de sus padres. Por otro lado, declara que legítimamente fue casada con Juan de Lira y tuvieron una hija llamada Micaela de Lira. Doña Francisca declara como hijo natural a «don Juan Carlos Ynga», hijo de Melchor Carlos Inca, vecino de la ciudad del Cusco señalando que dicho hijo está en los Reinos de España por orden y mandato de la Corona real. Don Melchor Carlos Inca dejó en posesión diferentes parcelas de tierras así como Ichobamba y Limatambo. So-

12 AGI. Lima, 472 (1563-1761), f. 5. «Expediente de Don Juan Bustamante Carlos Inca, sobre la sucesión en el estado de Oropesa y peticiones. Carta escrita al Virrey de Lima marqués de Villa García por el dicho Juan de Bustamante Carlos Ynga desde la dicha ciudad del Cuzco con fecha 8 de enero de 1738». 
bre las tierras de Chinchaypuquio, indica que los yanaconas están obligados a servirle a ella, como a madre de Juan Carlos Inca; todo esto, en virtud de la donación que le hicieran don Melchor Carlos Inca y doña María Esquivel. Doña Francisca parece que tuvo una predilección sobre las tierras de Chinchaypuquio adquiriendo casas y huertas del «tiempo de Ynga» de García Sape Tupa bajo consentimiento de doña Juana Asarpay, quienes eran descendientes del Inca Huayna Cápac. ${ }^{13}$ En 1627, Juan Melchor Carlos Inca heredó de su padre el título de Caballero de la Orden de Santiago.

Doña Francisca declara, también, como sus hijos naturales -después de haber enviudado-, a Jerónimo de Quesada, hijo de Jerónimo Sánchez de Quesada, a Pedro de Hermosa, hijo de Jerónimo Hermosa de Redondo y al menor, Antonio Vílchez, hijo de Francisco de Vílchez. En la distribución de sus bienes, doña Francisca menciona a su hija legítima Micaela de Lira así como a sus hijos naturales. Sin embargo, no aparece ninguna herencia para su hijo Juan Melchor Carlos Inca, siendo necesario destacar la persona de doña Francisca de Chávez, quien, según su propio hijo Juan Carlos Inca o Juan Melchor Carlos Inca, se habría llamado doña Francisca Quispe Sisa. ${ }^{14}$

Manuel Casado (2005) ha realizado un estudio sobre la descendencia de don Melchor Carlos Inca, en base a documentos del Archivo Histórico de Protocolos de Madrid (AHPM). ${ }^{15}$ Se encontraron dotes, pago de deudas, escrituras de ventas, la venta de algunas joyas y poderes para cobrar. Lo más interesante, por los da-

13 ARC. Protocolo Notarial, Cristóbal de Lucero (interviene López de Paredes), Prot. 165 (1627-1628), ff. 360-364v. Testamento de doña Francisca de Chávez. Cusco, 7 de agosto de 1627.

14 ARC. Protocolo Notarial, Cristóbal de Lucero (interviene López de Paredes), Prot. 165 (1627-1628), ff. 360-364v. Testamento de doña Francisca de Chávez. Cusco, 7 de agosto de 1627.

15 Ver también Temple (1949-1950). 
tos que se avistan, fue revisar el testamento de don Juan Melchor Carlos Inca, fechado el 4 de mayo de 1630 pero antes debemos referir lo siguiente: el pleito con la madrastra finalmente se dirimió por una parte entre Juan Melchor Carlos Inca, María Coya (novicia en el monasterio de las Bernardas de Vallecas), además de los apoderados de Juan Yupanqui Inca y Melchor Clara Coya (monja profesa en el convento de Nuestra Señora de los Remedios de la ciudad del Cusco), y por otra, con el apoderado de María Silva, viuda de Melchor Carlos Inca. Doña María Silva, con la satisfacción de 1,200 ducados, se aparta de sus pretensiones en el pleito. Don Juan Melchor Carlos Inca, quien había llegado para educarse en España siguiendo las instrucciones del virrey Marqués de Montesclaros, contrajo matrimonio con doña Jerónima de Negrete Gilimón (Casado 2005: 62). Apesadumbrada, hacia 1630, la viuda doña Jerónima Negrete había quedado en extrema necesidad.

\section{Los Carlos InCa del Siglo XVII}

A la muerte de don Fernando Inca, don Cristóbal Carlos Inca fue ratificado en el oficio de Alcalde Mayor desde 1646 hasta 1681. Don Cristóbal Carlos Inca fue el hijo natural de don Melchor Carlos Inca, caballero de la Orden de Santiago y de doña Juana Ynquil Guainacana quien quedara embarazada antes del viaje a España de don Melchor Carlos Inca. Este hijo fue llamado don Cristóbal Carlos Inca y, en su testamento fechado en 1681, declara haber sostenido un primer matrimonio con doña Andrea Auñón con quien tuvieron como hijos a don Melchor Carlos Inca, don Juan Carlos Inca, doña Elena Carlos, doña Ana Carlos y doña Thomasina Carlos. En segundas nupcias contrae matrimonio con doña Beatriz Valdez, pero no tuvieron hijos. Respecto a la posesión del oficio de Alcalde Mayor, declara que el «Rey Nuestro Señor le debe y en 
su nombre la Caxa Real por sus servicios y salarios, de 28 años de Alcalde Mayor de las Ocho Parroquias». ${ }^{16}$

Don Cristóbal Carlos Inca fue otro personaje importante dentro de la sociedad cusqueña. Quizá para mantener su prestigio y vivir ostentosamente, tuvo que vender a diferentes personas cantidades de tierras que había heredado de don Melchor Carlos Inca. En 1647, otorga en venta a don Jerónimo Costilla 50 fanegadas de tierras en Cotabambas por un valor de 400 pesos e hipotecó un solar y casa en la parroquia de San Cristóbal, a favor de la capellanía que mandó fundar doña Juana Chimbo Urma. En 1648, vio casarse a su hija doña Elena Carlos Quispe con don Pedro Casquina Condor, cacique principal y gobernador de los Chachas y Uchachas de los Condesuyos de Arequipa. Para el mantenimiento de dicho matrimonio dio por vía de dote 3,000 pesos, pero doña Elena poco después de su matrimonio habría muerto; por recuperar los 3,000 pesos que dio por dote de su hija, otorgó poder a su hijo don Melchor Carlos Inca, para que hiciera el cobro de los bienes de don Pedro Casquina. ${ }^{17}$ En 1656, obtiene en arrendamiento las tierras pertenecientes a los «aillus Vicaquirao»y «Apomayta», reducidos en la parroquia de San Sebastián, donde sus caciques optaron por arrendarlas para pagar sus tasas y tributos.

Poco antes de su muerte, otorgó dos escrituras importantes. ${ }^{18}$ La primera es una escritura de aprobación otorgada en la parroquia de San Cristóbal, a favor de Ruiz de Barba, por las tierras de Umas-

16 ARC. Bustamante Alfonso, Prot. 13 (1681-1682), f. 402. «Testamento. Don Cristóbal Carlos Ynga, hijo natural de don Melchor Carlos Inga, caballero de la Orden de Santiago y de doña Juana Yquil Guainacana» (Cusco, 24 de noviembre de 1681).

17 ARC. Mesa Anduesa Lorenzo, Prot. 193 (1661), f. 17v. «Don Cristóbal Carlos Inga, vecino y alcalde mayor de las ocho parroquias, otorga poder a don Melchor Carlos Inga, su hijo para cobrar de los bienes de Pedro Casquina» (18 de enero de 1661).

18 Aunque estas escrituras habrían sido falsificadas por el escribano Saldaña, según afirma la investigadora Kathryn Burns (comunicación personal). 
bamba que estaban en términos del pueblo de Chinchero. Dichas tierras fueron rematadas a pedido de los señores jueces en cantidad de 2,100 pesos, de cuya cantidad era deudor don Cristóbal Carlos Inca, «por los tributos de los indios mostrencos cuya cobranza estaba a su cargo». Esta escritura se aprobó, en 1683, pero con la exclusiva aclaración de que dichas tierras de Umasbamba estaban valoradas en 7,000 pesos. ${ }^{19}$ Dos años después vendió unas tierras en el valle de Ichopampa nombradas Chamancalla, Tocucacca, Chachauno, Nuñua, Yachacha, Vilcasa, Toctopuquio, Hachapay, las cuales constaban de 60 fanegadas de tierras que heredó de su padre, don Melchor Carlos Inca, a favor de don Agustín Jara de la Cerda y doña Josefa de Valera y de los Ríos por la cantidad de 500 pesos. $^{20}$

Don Cristóbal Carlos Inca, incluso en ese momento, seguía poseyendo la mayor cantidad de bienes que había heredado, como son las casas principales en la parroquia de San Cristóbal, las haciendas de Ichopampa, Chamancalla, Umasbamba, Siquecancha y las huertas de Paccayhuaycco y Otcuti en Chinchaypuquio. ${ }^{21}$

Me parece importante señalar otra línea parental de los Carlos Inca, porque, en 1682, encontramos a don Florián Carlos, don Lázaro Carlos Ynquiltopa y don Lucas Carlos, hijos legítimos y herederos de don Melchor Carlos Inca, nietos de Juan Carlos y bis-

19 ARC. Saldaña, Joan de, Leg. 295 (1679-1683), f. 98. «Aprobación de venta. Otorgada por don Cristóbal Carlos Inga, hijo de don Melchor Carlos Inga caballero de la Orden de Santiago, nieto de Guayna Capac Inga, a favor de Joseph Ruis Barba de las tierras de Umasbamba» (16 de julio de 1683).

20 ARC. Saldaña, Joan de, Prot. 296 (1685), f. 139v. «Venta de don Cristóbal Carlos Paullo Tupa Inga hijo de don Mellchor Carlos Inga y doña Beatriz de Valdés su mujer, naturales de la parroquia de San Cristóbal, a favor de don Agustín Jara de la Cerda» (8 de marzo de 1685).

21 Como señaláramos en nuestra tesis (2004: 24-25), estas huertas, más las huertas de Challas «eran conocidas por huertas del Inca Huayna Capac, las cuales fueron heredadas primero por Cristóbal Paullo Ynga, Carlos Ynga, Melchor Carlos Ynga y don Cristóbal Carlos Ynga, esta descendencia continuó en la posesión de esta huerta aun en el siglo XVIII». 
nietos de don Juan Cusigualpa, naturales de la parroquia de San Cristóbal. Esta familia sostenía un pleito sobre 12 papacanchas de tierras que se encontraban sobre la «fortaleza del inga». Señalaban que «estas tierras habían quedado por bienes de don Juan Cusigualpa, las cuales había heredado el dicho don Juan Carlos nuestro abuelo del dicho don Juan Cusigualpa». De estos había heredado don Melchor Carlos Inca, sin embargo desde que murió don Juan Carlos, los títulos de estas tierras se habían perdido y en 1682 los volvieron a encontrar entre los bienes de don Martín Quispe Topa. De esta manera, intentaron recuperar dichas tierras, pero el poseedor de estas hasta entonces, que era don Diego de Coba, respondió que tenía posesión de más de 35 años. ${ }^{22}$ Es muy probable que en 1659, sea don Melchor Carlos Inca quien aparece con el nombre de «don Mellchor Ynga Sapaca» siendo Alférez Real; ya hacia 1685 encontramos a don Florián Carlos Inquiltopa como uno de los veinticuatro electores. En 1720, don Francisco Carlos Ynquiltopa fallece como consecuencia de una epidemia general.

Después del fallecimiento de don Cristóbal Carlos Inca, el oficio de Alcalde Mayor, a pesar de haber establecido como herederos a sus hijas y a Juan Carlos Inca, pasó a manos de otros descendientes. Podríamos señalar que el control y monopolio del oficio de Alcalde Mayor, en manos de los descendientes de Huayna Cápac desde 1555 hasta 1681, había terminado con la muerte de don Cristóbal; por ello, este oficio hacia 1690 ya estaba en manos de otrosdescendientes, como don Melchor Quispe Sucso, quien fuera principal de la parroquia de San Sebastián.

22 ARC. Corregimiento, Leg. 22 (1680-1684), Cuad. 9, f. 20 (19 de junio de 1682). «Autos seguidos por Florián, Lázaro y Lucas Carlos Ynquiltopa, hijos legítimos y herederos de don Melchor Carlos Ynga y nietos de don Juan Carlos y bisnietos de don Juan Cusigualpa, naturales de la parroquia de San Cristóbal; con Diego de la Coba, sobre la posesión de 12 papacanchas de tierras donde dicen Mutcapuquio, encima de la fortaleza del Ynga» (contiene varias escrituras de venta de dichas tierras desde 1593). 
Pareciera que los principales de San Sebastián se apoderaron del oficio de Alcalde Mayor, en vista de que en 1692, «don Juan Sicos Ynga», próspero mercader en la ciudad del Cusco, detentaba el oficio de Alcalde Mayor e hizo una demostración de ese poder el 22 de agosto de 1692, en la procesión y fiesta de Nuestra Señora de Loreto. Allí fue visto por los testigos, desfilando delante del anda de la imagen por toda la plaza de la ciudad del Cusco. Portaba en la cabeza la mascapaicha de la borla colorada, la cual tenía incrustaciones de perlerías y joyas muy preciosas (Cahill 2000: 161). La advocación de Nuestra Señora de Loreto fue también una cofradía importantísima fundada en la Compañía de Jesús. Don Juan Sicos fue hijo de don Diego Sicos, principal y alcalde ordinario de la parroquia de San Sebastián. El momento parece propicio para iniciar la reivindicación de los descendientes incas cuya memoria era remota, o que fueron marginados del derecho a llevar la mascapaicha, razón por la cual fueron rezagados de muchos privilegios como alcalde mayor, alguacil mayor y quizá el derecho de alferazgo. El despertar de este sector de la descendencia inca, se debe a la espléndida participación de Juan Sicos como Alcalde Mayor de las Ocho Parroquias en la fiesta de la Virgen de Nuestra Señora de Loreto.

Todo este proceso de transferencia habría marcado una época donde los descendientes de Huayna Cápac perdieron todos los privilegios, pues para ellos era un gran honor asumir el cargo de Alférez Real, Alcalde Mayor y Alguacil Mayor. Los incas del burincuzco, se apoderaron de estos cargos y de esta manera aquellos que durante mucho tiempo fueron relegados en su posesión empezaron a detentarlos.

\section{El entierro de los Carlos InCa}

La disposición o la cláusula sobre el entierro de los restos mortales del testamentario es un acto en el que se dispone la ubicación de su sepultura, según la inclinación a la orden religiosa de su prefe- 
rencia o por la jurisdicción del feligrés en la iglesia y parroquia. Las familias importantes y distinguidas de la sociedad cusqueña tenían la costumbre de instituir y establecer una capilla del santo o santa de su predilección al interior de la iglesia donde celebraban las misas encargadas. Debajo de ellas construían criptas donde la familia en sus distintas generaciones era enterrada bajo disposiciones especiales o cláusulas del testamento.

Es así que, para 1582, don Carlos Inca dispone a través de su testamento, que su cuerpo sea amortajado en el hábito de Nuestra Señora de las Mercedes y enterrado en la iglesia y monasterio de San Francisco, en la capilla de Nuestra Señora de Guadalupe. ${ }^{23}$ Esta capilla y «un sitio» estaban ubicados junto a la Capilla Mayor, por donde se entraba a la sacristía. Según la declaración de don Carlos, dicha capilla se compró con su propio dinero, porque el entierro que adquirió su padre don Cristóbal Paullo Inca fue en el sitio de San Blas, donde por primera vez se estaba fundado el monasterio de San Francisco. ${ }^{24}$ Don Carlos Inca reitera que la capilla de Nuestra Señora de Guadalupe fue comprada con su propio dinero a través de una escritura, por lo que advierte a su hijo don Melchor Carlos Inca la imposibilidad de vender ni la capilla ni los ornamentos; asimismo, dispone que en dicha capilla no se sepulte ninguna persona contra la voluntad de sus herederos porque así lo determina. Para el mantenimiento y seguridad de la capilla, don Carlos Inca otorga

23 La capilla viene siendo estudiada por Rosa Canasa Gutiérrez, especialista en guidismo de historia del arte colonial en los monumentos religiosos de la ciudad del Cusco.

24 José María Blanco describe la ubicación de la iglesia y convento de San Francisco, que fue fundado en 1534, por el padre fray Pedro Portugués, en el barrio de Tococachi, aunque señala equivocadamente San Cristóbal lo que era en realidad San Blas. En 1538, se hizo una nueva fundación en el barrio de Casana. Después en 1549, se trasladó a su ubicación actual. Este sitio fue de Juan Rodríguez de Villalobos, quien cedió a los padres fray Pedro Portugués y fray Fernando Hinojosa, quienes compraran la plaza siendo corregidor Garcilaso de la Vega (Blanco 1974: 228). 
3,000 pesos, para que en razón de ella se instituya censo y renta sobre bienes bien acreditados. Con el tributo y renta de ella, cada año se oficiarían misas por su alma y la de sus familiares perpetuamente en la capilla de Nuestra Señora de Guadalupe. La administración de la capilla quedó a cargo de su esposa doña María de Esquivel, de su cuñado Diego de Escobar e instituye como heredero universal y patrón de esta memoria a su único hijo Melchor Carlos Inca, quien después cedería estos derechos a sus nietos mayores para de tal forma suceder y mantener el mayorazgo ${ }^{25}$. Es importante constatar que en 1569 «don Cristóbal Concha Auqui Ynga», natural de la ciudad del Cusco, pide que su cuerpo sea enterrado en la capilla de don Carlos Inca, en el monasterio de San Francisco. ${ }^{26}$ Esto confirma que la capilla y entierro de Nuestra Señora de Guadalupe fue establecida e instituida por el propio Cristóbal Paullo Inca.

Es necesario destacar que en 1549, don Cristóbal Paullo Inca fue quien instituyó la capilla de Nuestra Señora de Guadalupe para su entierro cuando todavía estaba ubicado el convento de San Francisco en Tococachi, donde posteriormente se fundó la iglesia de la parroquia de San Blas. Por esta razón, don Carlos Inca dispone que se oficien por el ánima de su padre veinte misas. Es así, como ya hemos explicado, que en 1582, don Carlos Inca, dispone que sus restos mortales sean enterrados en la capilla de Nuestra Señora de Guadalupe de la iglesia y convento de San Francisco, esto a su vez, fue dejado en herencia a su único hijo don Melchor Carlos Inca. Don Melchor a su vez falleció el 2 de octubre de 1610, en la villa de Alcalá de Henares, en el Real Colegio de Religiosos Calzados de San Agustín. Don Melchor Carlos Inca otorgó su testamento cerrado

25 ARC. Corregimiento, Leg. 66 (1699-1705), «Autos con Lazaro Dueñas con Bartolome Carlos Ynga, sobre 12 topos de tierras que vendieron sin título a Mateo Aristegui en la pampa de Punchao chacara», Testamento de don Carlos Ynca (Cusco, 27 de febrero de 1582), ff. 45v-48.

26 ARC. Notario Antonio Sanches, Prot. 21 (1569), f. 908, Testamento don Cristóbal Concha Auqui Ynga (Cusco, 13 de junio de 1569). 
ante el escribano del rey, Juan de Quintarnaga; el testamento cerrado se abrió el 4 de octubre de 1610: «en él pedía el traslado de sus restos a Cuzco para recibir sepultura en el Convento de San Francisco» (Casado 2005: 3). Igualmente, don Juan Melchor Carlos Inca otorga su testamento el 4 de mayo de 1630, dejando en la pobreza a su esposa doña Jerónima de Negrete Gilimón.

Doña Leonor de Soto, vecina en la parroquia de Santa Ana de Carmenca, dio poder al cura maestro Gaspar de Villagra, clérigo y presbítero de dicha parroquia para que otorgara su testamento. Doña Leonor era viuda de Garcí Carrillo, hija legítima del Adelantado don Fernando de Soto Caballero de Santiago y de doña Leonor Mama Ocllo. El cura Gaspar declara que doña Leonor Soto fue enterrada en el convento de San Francisco en la capilla de Nuestra Señora de Guadalupe, tras el entierro de don Melchor Carlos Inca. Sus restos mortales fueron acompañados por el cura y sacristán de la Parroquia de Hospital de Naturales y enterrados con el hábito de San Francisco. Los frailes del convento de San Francisco brindaron una misa rezada y cantada con diácono y subdiácono. ${ }^{27}$ Por otro lado, no siempre los descendientes de Paullo Inca se enterraban en la capilla de Nuestra Señora de Guadalupe, tal es el caso de doña Angelina Pilco Sisa Nusta, natural de la parroquia de Belén, hija de Cristóbal Paullo Inca y nieta de Huayna Cápac Ynga, quien pide que su cuerpo sea enterrado en el colegio de la Compañía de Jesús, en la capilla de Nuestra Señora de la Consolación de los Naturales. ${ }^{28}$

Es sumamente interesante observar cómo doña Juana Quispe Sisa Nusta, natural de la parroquia de San Cristóbal, hija legítima de «don Fernando Guaca Topa Pumacapi Ynga», nieta legítima de «Paullotopa Ynga», pide que su cuerpo sea amortajado en hábitos de San Francisco y enterrado en la iglesia de la parroquia de San

27 ARC. Notario, Juan de Olave, Prot. 249 (1611-1612), f. 515. Testamento de Leonor de Soto (Cusco, 20 de octubre 1610).

28 ARC. Notario, Luis Diez de Morales, Prot. 69 (1623-1624), Testamento de doña Angelina Pilco Sisa Nusta (Cusco, 23 de setiembre de 1623). 
Cristóbal, en la capilla mayor, donde «mis padres y abuelos están enterrados por ser, como soy eredera legitima de los suso dichos». ${ }^{29}$ Sin embargo, doña Juana declara que tiene una capilla de entierro con su bóveda, en el convento de San Francisco, en la capilla de Nuestra Señora de Guadalupe, la que le había heredado su abuelo, don Cristóbal Paullo Inca y pide que de dicha capilla gocen sus sobrinos «don Fernando Ynga y don Martín Quispi Topa, además de sus hermanos y sobrinos». Por otra parte, señala que tiene otra capilla y entierro en el mismo convento de San Francisco donde se ubica «Nuestra Señora de la Limpia Concepción de los Naturales». Dicha capilla, según la declaración de doña Juana, le costó a ella y a su esposo Marcos Coro y Santa Ángel, oficial y maestro pintor. Según su propia declaración, por dicha capilla y entierro, el convento recibió la cantidad de 1500 pesos, monto de la hechura del «Retablo Grande del Altar Mayor», que hiciera su esposo, desafortunadamente señala que no cuenta con títulos que confirmen su disposición debido a la pérdida de dichos documentos. ${ }^{30}$

Don Fernando Inca, Alcalde Mayor de las Ocho Parroquias de la ciudad del Cusco, hijo natural de don Martín Quispitopa Inca y de doña Francisca Balladares, también pide que su cuerpo sea sepultado en la misma capilla de Guadalupe donde se encontraba el entierro de sus padres y antepasados. ${ }^{31}$ Asimismo, don Martín Quispitopa Inca, natural de la parroquia de San Cristóbal, hijo de don Martín Quispitopa Inca y de doña Francisca de Balladares Coya, pide que se cuerpo sea amortajado en hábitos de San Francisco y enterrado en la mencionada capilla donde yacían sus padres y antepasados. ${ }^{32}$

29 ARC. Notario, Francisco de la Fuente, Prot. 111 (1633-1635), f. 322, Testamento de Doña Juana «quispi çiça ñusta» (Cusco, 30 de octubre de 1635).

30 ARC. Notario, Francisco de la Fuente, Prot. 111 (1633-1635), f. 323.

31 ARC. Notario, Juan Flores de Bastidas, Prot. 93 (1645-1647), f. 908, Testamento de don Fernando Ynga (Cusco, 11 de julio 1646).

32 ARC. Notario, Alonso de Bustamante, Prot. 11 (1676-1678), f. 270, Testamento de don Martín Quispitopa (Cusco, 3 de setiembre de 1678). 
Para 1681, el caso de don Cristóbal Carlos Inca es muy importante porque a pesar de haber declarado ser hijo natural de don Melchor Carlos Inca, caballero de la Orden de Santiago y de doña Juana Ynquil Guaina, en su testamento manda y pide que sus restos mortales sean amortajados con el hábito de San Francisco, solicitando ser enterrado en la capilla mayor de la iglesia de San Cristóbal. ${ }^{33}$ De esta forma, rompe la tradición de los «Carlos Inca» y no pide ser enterrado en la capilla de Nuestra Señora de Guadalupe del convento e iglesia de San Francisco, sino en la iglesia de su parroquia, la iglesia de San Cristóbal.

\section{A manera de ConClusión}

El siglo XVI significó el reordenamiento y reacomodo de la historia de los incas gobernantes, para ello la legalización de los descendientes incas ante la legislación de la estructura política colonial era un factor fundamental. En esta perspectiva, los Carlos Inca son un caso extraordinario que nos permite entender y explicar cómo proceden con la legitimación de la descendencia inca, para luego adoptar la calidad de español o mestizo. Es así como la personalidad y gestión de don Melchor Carlos Inca ante la Corona española presenta varias facetas.

En primer lugar, la limpieza de sangre de don Cristóbal Paullo Inca. Resulta que don Paullo era considerado hijo «bastardo» del Inca Huayna Cápac y de Añas Colque quien era hija de un Cápac de Guaylas y no era hermana del inca o «panaguarmi». Al respecto, don Melchor Carlos a través de los testigos de españoles y de nobles incas, intenta demostrar el matrimonio de su bisabuelo era de acuerdo a la costumbre y usanza de los incas, donde Añas Colque

33 ARC. Notario Alonso de Bustamante. Prot. 13, año 1681-1682. f. 402. Testamento de don Cristóbal Carlos Ynga. Cuzco 24 de noviembre 1681. 
adquiría el comportamiento de una coya, es de decir de una «panaguarmi», que así se nombraba legítimamente a la esposa del Inca. Los servicios prestados en la conquista a favor de su majestad eran oportunos, por ello fue privilegiado con diferentes encomiendas de indios. Por otro, le coronaron inca, como tal ejecutó las últimas fiestas incas y fue enterrado como todo un soberano inca. Por otro lado, don Carlos Inca es presentado con actitudes de un español, caballero y lenguaraz, y se casó con doña María Esquivel, mujer española.

En segundo lugar, la personalidad de don Melchor Carlos Inca es descrita a través de los testigos y su nacimiento es presentado como el de todo un «Cápac» o «Inca», que fue reconocido por todos los habitantes de la región del Cusco. Su padrino de bautizo, don Francisco de Toledo, fue resaltado. Es en este entender que se observa a don Melchor Carlos Inca como todo un benemérito español, legalizando el otorgamiento de mercedes de encomienda. Fue postor para adquirir los títulos de regidor en el cabildo del Cusco y con apetencia de ser Alférez General de la ciudad del Cusco. Una vez gestionados los títulos de las encomiendas que heredó de su padre y abuelo, procedió a la probanza genealógica y de los servicios prestados a favor de la Corona española. Con todos estos instrumentos, viajó a España y acudió ante la Corona para solicitar privilegios, logrando obtener la orden militar y religiosa de caballero de Santiago.

Finalmente, los Carlos Inca del siglo XVI y XVII lograron empoderarse como descendientes legítimos del Inca Huayna Capac, por lo que obtuvieron los cargos de privilegio como Alcalde Mayor, Alguacil Mayor y Alférez Real de los Incas de las Ocho Parroquias de la ciudad del Cusco. Don Melchor Carlos Inca fue una personalidad muy destacada y referida por sus familiares, por ejemplo, doña Juana Pilco Guaco, descendiente de don Felipe Túpac Amaro, decía que era «prima de don Melchor Carlos Inca». Don Cristóbal Paullo Inca y don Carlos Inca, su hijo, lograron establecer y constituir la 
capilla de Nuestra de Señora de Guadalupe, en el convento e iglesia de San Francisco de Cusco para el entierro de los descendientes y ascendientes de la familia de los Carlos Inca. Esta disposición y herencia fue custodiada celosamente y con mucha atención en los testamentos de los descendientes de los Carlos Inca.

\section{REFERENCIAS}

ARC Archivo Regional del Cusco

AGI Archivo General de Indias

BNM Biblioteca Nacional de Madrid

BAUER, Brian S. y Madeleine Halac-Higashimori

2013 Baltasar de Ocampo Conejeros y la Provincia de Vilcabamba. Cusco: Ceques Editores.

BLANCO, José María

1974 [1835] Diario de viaje del presidente Orbegoso al sur del Perú. Lima: PUCP-IRA.

Casado Arboniés, Manuel

2005 «Presencia de Melchor Carlos Inga de Amarilla en la corte de Madrid: la descendencia del Inca en tiempos de Quijote». Archivo per l'Antropologia e la Etnologia, n. 135, pp. 57-67.

CAHILl, David

2000 «The Inca and Inca Symbolism in Popular Festive Culture: The Religious Processions of Seventeenth-Century Cuzco». En: Peter T. Bradley y David Cahill (eds.). Habsburg Peru. Images, Imagination and Memory. Liverpool: Liverpool Univesity Press, pp. 88-162.

Lohmann Villena, Guillermo

1947 Los americanos en las ordenes nobiliarias (1529-1900). Madrid: CSIC. 
MacCormack, Sabine

2004 «inca o Español? las identidades de Paullo Topa Inca». Boletin de Arqueología de la Pontificia Universidad Católica del Perú, n. 8, pp. 99-109.

Temple, Ella Dunbar

1949-1950 «Los testamentos inéditos de Paullu Inca, don Carlos y don Melchor Carlos Inca. Nuevos datos sobre esta estirpe incaica y apuntes para la biografía del sobrino del Inca Garcilaso de la Vega». Documenta, vol. 2, n. 1, pp. 630-651.

VÁzquez de Espinoza, Antonio

1948 [ca. 1629] Compendio y descripción de las Indias Occidentales. Washington DC: Smithsonian Institution. 